Establishment. More recently he has been investigating problems of control involving a human operator, and of visual pattern recognition. He has examined also problems of muscle control and has studied principles and design of systems which 'learn from experience', with a view to their application to process control. It is anticipated that Dr. Uttley will take up his appointment early in the new year.

\section{Commonwealth Mycological Institute :}

Dr. S. P. Wiltshire

DR. S. P. Wiltshire, who has recently retired from his post as director of the Commonwealth Mycological Institute, entered as mycologist and assistant to the director (Sir Edwin Butler) in 1922. In 1933 he was appointed assistant director and editor, and director and editor in 1940. His quiet and self-effacing manner tends to hide a tenacity of purpose which has been invaluable to the Institute and of great worth to mycology in general. Thus he contrived the regular appearance of the Review of Applied Mycology, the initiation of a series of mycological papers and monographs, a series of distribution maps of plant diseases and a Review of Medical and Veterinary Mycology during what has been probably the most difficult period for publication ever known. In addition, he planned and supervised the general organization of the excellent new building which was opened last year.

\section{Dr. J. C. F. Hopkins}

Dr. J. C. F. Hopkins, who succeeds Dr. Wiltshire, is known mainly for his work on the diseases of tropical plants, first in Uganda, and then as chief botanist and plant pathologist to Southern Rhodesia. He recently published a book on "Tobacco Diseases". On his retirement from overseas in 1953 he was appointed assistant editor at the Institute. As so much of the work there is concerned with the diseases of crop plants of tropical regions, Dr. Hopkins's previous practical experience will stand him, and the Institute, in good stead.

\section{E. F. F. Chladni (1756-1827)}

A Great pionecr in the science of acoustics, Ernst Florens Friedrich Chladni was born of Bohemian parents at Wittenberg two hundred years ago on November 30, 1756. He graduated Dr. Jur. at Leipzig in 1782; but on the death of his father abandoned law for natural science, being particularly interested in sound and in music and being inspired by the work of Leonhard Euler and of Daniel Bernoulli. $\mathrm{He}$ studied the torsional vibrations of a pendulum and the longitudinal vibrations of strings and rods, and applied the latter to the determination of the velocity of sound in solids. He also measured the velocity of sound in media other than air by filling an organ pipe with the medium and taking the pitch of the note produced. Using brass plates clamped at the centre and excited by bowing at on $\theta$ end, and sprinkling sand on the vibrating plates, he obtained 'Chladni's figures', which he exhibited to the French Institute in 1809. Napoleon was so impressed by this demonstration that he gave Chladni 6,000 francs to enable him to have his book, "Die Akustilk" (Leipzig, 1802), translated into French. Chladni never held an official position, and he earned his living by trarelling in Germany, France, Italy, Holland, Denmark and Russia, where he delivered scientific lectures and gave recitals on an instrument which he had designed and constructed and. which he called a euphonium. He wrote numerous papers and treatises, including several on meteorites. He died at Breslau on April 3, 1827, leaving his money to the poor of his native town and his meteorites to the royal collection at Berlin.

\section{New Research Laboratories of Thorium, Ltd.}

Mr. G. H. BeEBY, chairman of Imperial Chemical Industries, Ltd. (Salt Division), and also of Thorium, Ltd., opened the expanded Research Laboratories of Thorium, Ltd., at IIford on November 14. Thorium, Ltd., specializes in the production of thorium and lanthanon chemicals and in the manufacture of polishing powders for glass and metal. Thorium metal is used mainly in special alloys for aircraft construction. Thorium oxide is used in some types of optical glass, as a refractory and in making incandescent mantles for pressure lanterns, etc. As thorium is a fertile element several times more abundant than natural uranium, it has a potential application in atomic energy production. The lanthanons are difficult to separate, so most of the commercially used materials are therefore mixtures freed from non-lanthanon impurities. The most widely used mixture contains about 50 per cent cerium and is called 'technical cerium'. This is used for making lighter flints, in the metallurgical field for improving the quality of many ferrous alloys, and in making special alloys and for improving the luminosity of carbon arc lamps. It also has uses in the chemical and paint industries and is an important component of the glasses used in welder's goggles. Cerium oxide is an excellent polishing material for glass and metal; materials containing 50-95 per cent cerium are used to make the polishing powder sold as 'Cerirouge'. 'Didymium' oxide, a mixture of praseodymium and neodymium oxides, is used to produce colours in glass, and pure neodymium oxide is used to give a spectacular red-blue colour to certain decorative glassware. Lanthanum oxide is also used in glass-making to produce special optical glasses. Samarium is used in making phosphors for fluorescent lamps. The research department of Thorium, Ltd., has a staff of about twenty, the research manager being Mr. R. J. Callow. Research is conducted mainly into methods of purifying and separating the materials produced by the firm, into methods for process control and into the properties of polishing powders. The new laboratories have a floor area of about $7,500 \mathrm{sq}$. ft., divided into five main laboratories of varying sizes, a pilot-plant room and ancillary space such as library, dark room, etc. At the opening ceremony, a number of items of work were shown.

\section{New Training School for Apprentices}

A NEW craft training school for apprentices employed by British Oxygen Engineering, Ltd., was opened at Angel Road, Edmonton, on November 15, by Mr. Robert Carr, Parliamentary Secretary to the Ministry of Labour. Since 1951, when the Company's new apprenticeship schemes were first put into operation, it was felt that there was a great need for a training school to be completely separate from the production workshops. It would provide apprentices embarking on a five-year course with the firm with a real knowledge and appreciation of basic engineering craft skills, and would enable them to assimilate more quickly the training they received in the production workshops and technical offices, so that they could carry out their jobs with maximum efficiency. The 